mental model of acute respiratory distress syndrome. JAMA 2003; 289(16):2104-I2.

2. Ranieri VM, Suter PM, Tortorella C, De Tullio R, DayerJM, BrienzaA, etal. SlutskyAS. Effect of mechanical ventilation on inflammatory mediators in patients with acute respiratory distress syndrome: a randomized controlled trial. JAMA 1999; 282(I):54-6I.

3. Ranieri VM, Giunta F, Suter PM, Slutsky AS. Mechanical ventilation as a mediator of multisystem organ failure in acute respiratory distress syndrome. JAMA. 2000 Jul 5;284(I):43-4.

\section{Ginecologia \\ VOZ E MUDANÇAS VOCAIS APÓS A MENOPAUSA}

Boulet \& Oddens $(1996)^{2}$ relatam que após a menopausa ocorrem mudanças na voz, decorrentes do impacto do hipoestrogenismo sobre a laringe e que foram confirmadas pelos esfregaços das pregas vocais que se mostraram atróficos e semelhantes àqueles do colo uterino (Abitbol \& Abitbol, 1998)'. Esse último estudo, realizado em 100 mulheres após a menopausa, constatou expressivas alterações laríngeas e vocais.

\section{Comentário}

Nos estudos acima, descritos e realizados com cantoras na Bélgica, Holanda, Austria e com profissionais da voz na França, apesar das mulheres revelarem conhecimento da importância da emissão vocal em suas atividades e terem refinamento auditivo para perceberem as alterações, um significativo número delas não procurou especialistas com o objetivo preventivo de retardar ou amenizar os agravos da redução hormonal do climatério e do envelhecimento sobre o processo vocal.

Em investigação qualitativa realizada por nós na cidade de Curitiba ${ }^{3}$ - Paraná, constatamos que a produção vocal é utilizada na comunicação para o estabelecimento de critérios relacionais e autoreflexão na vida cotidiana. 0 processo vocal foi considerado motivo de atenção pessoal para uma parcela expressiva de mulheres após a menopausa, não profissionais da voz; o estudo evidenciou, também, que as alterações vocais estabelecem conflitos ou contradições na constituição da nova identidade, sugerindo, por isso, que os fatores biopsicossociais devam sempre ser considerados como importantes elementos de repercussão sobre a voz (Machado, Aldrighi \& Yunes*, 2003) $)^{3}$.

Lindholm (1997), ao investigar a intensidade vocal na fala espontânea e na leitura, em mulheres após a menopausa que não utilizavam a voz profissionalmente, averiguou que a terapia de reposição hormonal atua como importante fator protetor aos agravos da voz no climatério. Abitbol \& Abitbol (1998)', por outro lado, indicam a reeducação vocal, caso a sintomatologia persista após três meses da terapêutica medicamentosa.

Do exposto, é importante alertar os profissionais de saúde que atendem mulheres no climatério, especialmente aquelas que utilizam a voz como principal instrumento de trabalho, objetivando não só manter o desempenho adequado na ocupação exercida, mas também a qualidade de vida após a menopausa.

\section{Maria Aparecida M. de P. Machado}

José Mendes Aldrighi JoÃo YUNES*

* IN MEMORIAN

Referências

I. Abtibol J, Abtibol B. Voix et menopause: crepuscule des divas Contracept Fertil Sex 1998; 26:649-55.

2. Boulet MJ, Oddens BJ. Female voice changes around and after the menopause-an initial investigation. Maturitas 1996:23: 15-21. 3. Machado MAMP. Tese de Doutorado a ser defendida no Departamento de Saúde Materno-Infantil da Faculdade de Saúde Pública da Universidade de São Paulo, 2003.

4. Lindholm P, Vilkman E, Raudaskoski T, Suvanto-Luukkonen E, Kauppila A. The effect of postmenopause and postmenopousal HRT on measured voice and vocal symptons. Maturitas 1997; 28:47-53.

\section{Medicina Baseada em Euidências}

\section{MANOBRAS DE RECRUTAMENTO PULMONAR NA SDRA}

O tratamento da síndrome do desconforto respiratório agudo (SDRA) tem sido motivo de importantes controvérsias na terapia intensiva. A mortalidade da SDRA oscila em torno de $30 \%$ a $60 \%$. Nenhuma abordagem tera- pêutica, exceto a estratégia ventilatória (ventilação protetora-PEEP elevado e baixo volume corrente com a finalidade de abrir os pulmões e mantê-los abertos), apresentou impacto na sobrevida desta síndrome. Os maiores temas para a controvérsia são a manobra de recrutamento alveolar e o uso de elevados níveis de pressão positiva no final de expiração(PEEP).

\section{Comentário}

Em seu artigo, Carmen Valente Barbas ressalta a importância da tomografia computadorizada de tórax no diagnóstico e na definição da estratégia ventilatória a ser empregada, as evidências experimentais sobre a lesão associada à ventilação mecânica (hiperdistensão alveolar, abertura e colapso cíclicos dos alvéolos, biotrauma), e o papel da estratégia ventilatória protetora na lesão pulmonar em animais de experimentação. Enfatiza ainda a importância da manobra de recrutamento alveolar para tornar a distribuição de gás mais homogênea, descreve possíveis métodos de recrutamento alveolar, destacando de forma especial a manobra de recrutamento progressivo intermitente, e a importância da titulação da PEEP para a manutenção de uma ventilação mais homogênea. Tal manobra consiste na elevação progressiva dos níveis de PEEP $(25,30,35,40$ e 45 $\mathrm{CmH}_{2} \mathrm{O}$ ) até alcançar um plateau de pressão em torno de $60 \mathrm{cmH}_{2} \mathrm{O}$. Tais dados são muito relevantes, pois evidências cada vez mais fortes têm demonstrado o impacto desastroso, nos pulmões e em órgãos à distância (como os rins e os intestinos), da adoção de uma estratégia ventilatória inadequada.

Além disso, a autora projeta para o futuro a importância de métodos de monitorização pulmonar à beira do leito, como a tomografia de impedância elétrica, cujo objetivo consiste em analisar de forma contínua e não-invasiva a distribuição de gás nos pulmões durante a ventilação artificial. Este novo método poderá ser uma ferramenta extremamente útil na titulação fina da ventilação mecânica, contribuindo para a redução da mortalidade desta síndrome.

\section{Gustavo faissol Janot de Matos}

Referência

Barbas CSV. Lung recruitment maneuvers in acute respiratory distress syndrome and facilitating resolution. Crit Care Med 2003;3I(4):S265-S7I. 